\title{
Digital transformation: Five recommendations for the digitally conscious firm
}

\author{
Ted Saarikko, Ulrika H. Westergren*, Tomas Blomquist
}

Umeå University, 90187, Umeå, Sweden

\author{
KEYWORDS \\ Digital transformation; \\ Digitization; \\ Digitalization; \\ Internet of Things; \\ Digital consciousness
}

\begin{abstract}
Digital transformation is one of the key challenges facing contemporary businesses. The need to leverage digital technology to develop and implement new business models forces firms to reevaluate existing capabilities, structures, and culture in order to identify what technologies are relevant and how they will be enacted in organizational processes and business offerings. More often than not, these profound changes require firms to revisit old truths as they develop strategies that thread the needle between beneficial innovation and harmful disruption. This article uses the Internet of Things (IOT) as a backdrop to demonstrate the concerns associated with transformative technologies and offers five recommendations as to how firms can develop the strategies needed for digital transformation and become digitally conscious: (1) Start small and build on firsthand benefits; (2) team up and create competitive advantage from brand recognition; (3) engage in standardization efforts; (4) take responsibility for data ownership and ethics; and (5) own the change and ensure organization-wide commitment. As such, this article shows that digital transformation should be a top management priority and a defining trait of corporate business strategy, and that by becoming digitally conscious, firms may get a head start on their transformation journey.

(C) 2020 Kelley School of Business, Indiana University. Published by Elsevier Inc. This is an open access article under the CC BY-NC-ND license (http://creativecommons. org/licenses/by-nc-nd/4.0/).
\end{abstract}

* Corresponding author

E-mail addresses: ted.saarikko@umu.se (T. Saarikko), ulrika.westergren@umu.se (U.H. Westergren), tomas.blomquist@umu.se (T. Blomquist)

\section{The challenge of digital transformation}

Digital transformation is one of the key challenges facing businesses today. Miniaturization and the commercialization of mobile computing have made the essential building blocks smaller, cheaper, and more capable than ever (Saarikko, 
Westergren, \& Blomquist, 2017). Indeed, one of the salient aspects of digital transformation is that access to the technology itself is rarely a problem. Instead, it is the ability to rapidly develop and implement viable digital business models that is at the heart of the issue (Hess, Matt, Benlian, \& Wiesböck, 2016). In the words of Kane, Palmer, Phillips, Kiron, and Buckley (2015): "Strategy, not technology, drives digital transformation." This indicates that firms need to develop competencies in leveraging digital technology for business purposes. Developing such digital consciousness is the focus of this article.

The rate at which digital technology is able to spawn new "smart" products and services is matched only by its ability to extend the reach and range of social interactions via ubiquitous infrastructure and malleable platforms (Nambisan, Wright, \& Feldman, 2019). Firms are feeling the pressure not just to alter their existing business models but also to operate a portfolio of different business models in order to cope with increasingly fickle customers who demand both flexibility and personalization of products and services ( $L i, 2018)$. But radically altering one's business model(s) and organization to leverage new technology is neither simple nor straightforward. It involves stepping out of one's comfort zone and possibly eliminating practices that employees and customers have come to expect or even take for granted.

Previous research has shown that digital transformation causes enterprises to rethink the very foundation of who and what they are. For instance, recent layoffs at General Motors were described as "existential," as the century-old Fortune 500 company was not merely responding to a periodic slump in sales but rather refocusing its whole organization to offer new digitized products and digitalized business models. This came with the realization that in the past 15 years there had been a consistent drop in the need for mechanical skills such as machine operating and tool grinding, while the demand for computer network-support specialists had skyrocketed (Muro \& Maxim, 2018). Reassessing existing skills and capabilities and how they are combined is one way to transition from functional silos to crossfunctional teams that can accommodate the interdisciplinary nature of innovative products and services (Porter \& Heppelmann, 2015; Vial, 2019). But firms must also consider how new technology can create whole new value propositions and business models, and how it can transform not only how business is done but also what business is (Krotov, 2017). The ability to stay relevant and competitive in the wake of massive and rapid technological development thus requires digitally conscious business strategies that thread the needle between purposeful development and tumultuous disruption.

This article builds on findings from three distinct types of firms-product-oriented, serviceoriented, and technology-oriented firms-regarding their outlook on and experiences with the Internet of Things (IoT) and how it can be used to digitally transform their businesses. The IoT, with its ability to connect products, people, and places, is predicted to have a deep and profound impact on organizations. With the evolution of the IoT through the development of cloud computing, miniaturization, smart sensors, and mobile technology, objects can not only be identified and located but can collect, process, and transmit context-aware data through time and space (Greengard, 2015; Kortuem, Kawsar, Fitton, \& Sundramoorthy, 2010; Lee \& Lee, 2015). This in turn creates new opportunities for firms. A deeper understanding of a product in use can prevent costly unplanned stops and product failure, and it can enable the service organization to adapt its business model to the benefit of both the supplier and customer. With a connected product, a supplier can maintain regular contact with the customer without relying on extra time-consuming manual work, and the enhanced information may ultimately lead the firm to sell its product as a service or function rather than a piece of hardware. The loT offers a wealth of new opportunities for the development of both products and services based on greater insight into individual customer needs and preferences (Brody \& Pureswaran, 2015; Porter \& Heppelmann, 2014) and can be used to improve both process efficiency and human productivity (Balakrishna, 2012). As such, we find it a current, relevant, and engaging technological paradigm that provides a context for exploring the digital transformation of firms.

Even though technical barriers have eroded away and the digital landscape has expanded with new possibilities, technology does not automatically bring added convenience or value unless firms carefully consider the context into which it is introduced and how to derive any practical or monetary benefits. Indeed, some refer to digitized products and services as "socio-cyber-physical offerings," highlighting that value is only extracted through a judicious intertwining of physical, technical, and social systems (Ng \& Wakenshaw, 2017). Many organizations are still slow to embrace new possibilities, and those that do are faced with a new set of challenges in handling this complex landscape defined by both rapid technological 
development and slower organizational processes (Matt, Hess, \& Benlian, 2015). But the risks associated with inaction may be even higher, as history has shown that digital technologies in particular can topple industry giants who fail to change with the times (Nylén \& Holmström, 2015). Previous research suggests that managers are often unaware of the different options and elements that they should take into consideration before diving headfirst into digital transformation (Hess et al., 2016). We propose that by becoming digitally conscious - that is, by developing an understanding of the opportunities, implications, and limitations in moving from a generic technological paradigm to a specific application, and by understanding how they are contingent upon concurrent social, cultural, and judicial systems - firms can become better equipped to take on new and transformative technologies. Set against the backdrop of the emerging loT, this article provides an empirically grounded study of digital transformation and offers five recommendations for aspiring digitally conscious firms to consider as they embark on their digital transformation journeys.

\section{Why digital technologies prompt transformation}

It is widely recognized that as information is increasingly digitized and mobile devices accelerate in pervasiveness and processing power, an arena for innovation is opened up-one in which physical and digital components are combined (Porter \& Heppelmann, 2014). Recent research (e.g., Henfridsson; Nandhakumar; Scarbrough, \& Panourgias, 2018; Nambisan, 2017) has highlighted how the unique properties of digital technology enable new types of innovation and entrepreneurship that are different from the analog processes of the industrial era. Two distinctions are worth highlighting. First, digital technologies permit loose couplings between components, meaning that innovation is less restricted by existing architectural hierarchies and dependencies. Hence, any given technological baseline (e.g., a digitized product or digital system) can rapidly spawn several distinct offshoots of different types and purposes. Second, digital technologies are imbued with low barriers to entry, meaning that even small entrepreneurs have few restrictions to transforming innovative ideas to viable market offerings. These digital entrepreneurs can in some cases be disruptive to incumbents (e.g., the way ride-sharing services, such as Uber, have challenged the taxi industry).
The rapid pace of digital innovation is particularly challenging as firms design hybrid or smart products that incorporate digital components. Products equipped with smart sensors form interconnected systems that collect, store, and transmit data about the products and their environment to cloud servers or back-office systems (Baines \& Lightfoot, 2013). Although some of the underlying technologies have been in use for a long time, with radio-frequency identification (RFID) tags being attached to everything from clothing and cars to animals and pharmaceuticals, their main purpose to date has been in identifying and tracking specific objects. Today, digital infrastructure extends all the way from backoffice servers to frontline activities thanks to the development of cloud computing, mobile technology, middleware, miniaturization, and smart sensors. With the expanding loT, objects can not only be identified and located but can collect, process, and transmit context-aware data through time and space, enabling new possibilities for product and service development (Lee \& Lee, 2015). Virtually any occurrence can be digitized, analyzed, and monetized. Data collected from products in use make it possible for suppliers to efficiently monitor products and offer services after the sale. Suppliers can thus gain insight into where products are located, how they are used, and whether they are working optimally or in need of maintenance. If data from several connected products are combined, flows and processes can be analyzed to find patterns and behaviors. With developed algorithms, decisions can be made about how services should be performed or how processes should be optimized. The loT thus enables the creation of situational, smart, attractive, and efficient goods and services.

Digital technology can be either transformative or disruptive depending on one's perspective and, more importantly, one's ability to harness its potential. It can either dislodge a firm from a competitive market position or serve to improve operational efficiency, empower frontline employees, inspire new market offerings, or indeed create entirely new industry niches. But this potential will not come to pass without a thorough understanding of digital technology in itself and just how it is relevant to a firm's own specific circumstances. Any firm seeking to make hay of digital technology must be willing to adapt its strategies and capabilities to accommodate new ways of perceiving and creating value. As an initial step, firms must better understand digital transformation and recognize that it is not a homogeneous concept. 


\section{Digital domains: Digitization, digitalization, and digital transformation}

As digital technology diffuses into industry, the economy, and society, it becomes increasingly necessary to distinguish between the different phenomena that emerge where the physical and virtual worlds intersect. At a bare minimum, one needs to differentiate between digitization, digitalization, and digital transformation, as well as what they signify in terms of scale and scope. Figure 1 shows how the three domains relate to one another, with digitization as a component of digitalization - which, in turn, is subsumed under digital transformation.

Digitization is the technical process of converting analogue signals to digital signals (Tilson, Lyytinen, \& Sørensen, 2010). This process permits the decoupling of form, function, and access, and it is a fundamental precondition for everything from smartphones to artificial intelligence. The way we access music provides us with a simple yet illustrative example of the power of digitization. As long as music is stored in an analog format (e.g., on a vinyl record), there are tight couplings between form, function, and access. That is, one cannot easily separate the data (the music) from the medium (the record), and it can only be accessed using a specific technology (a record player). But when music is digitized, it may be distributed in different formats (e.g., MP3, FLAC) using different media (e.g., physical disc, online streaming), and it may be accessed via multiple devices (e.g., CD player, computer, smartphone). While the aforementioned example of music describes the transition from analogue to digital information, digitization also encompasses how one captures physical activities and converts them into virtual representations. This form of digitization affords products and devices the ability to capture

Figure 1. Digital domains

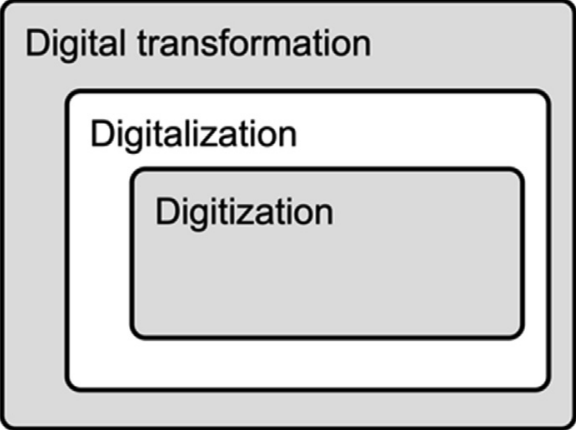

and convey location, velocity, temperature, humidity, vibrations, and other measurements as digitized data. When coupled with powerful algorithms, these data are essential to today's smart products that operate autonomously or with remote supervision (Porter \& Heppelmann, 2014). While the task of digitization is a complicated process that requires technical expertise, it can largely be outsourced or managed by a relatively small group of experts, and it is thus insulated from other aspects of an organization.

Digitalization is the sociotechnical process of leveraging digitized products or systems to develop new organizational procedures, business models, or commercial offerings (Brynjolfsson \& McAfee, 2014). While the words "digitization" and "digitalization" are often used interchangeably, there are important conceptual differences. Whereas digitization describes a technology-or system of technologies - in terms of what it is and its capabilities, digitalization answers why this technology is relevant to a specific process or organization. Returning to music as an example, the separation of content and medium has enabled iTunes and Spotify to redefine how we access and consume audio entertainment. Moreover, streaming audio services have redefined the underlying business model by changing the manner in which performers, producers, and distributors are compensated. Digitalization also affects how we use physical products-for instance, in the socalled sharing economy, multiple users can access and use the same product, thus shifting the nature of business from product retail to product access (Kathan, Matzler, \& Veider, 2016). Industrial machinery is undergoing a similar transition, with suppliers keen to offer all-inclusive service contracts so that customers pay per product use rather than product purchase. Digitized machinery makes this digitalized business model more appealing to suppliers, who can easily supervise their products in the field, reducing the risk entailed by their responsibility for continuous performance. Furthermore, they can monitor machine conditions and dispatch technicians to perform predictive maintenance before costly breakdowns occur (Saarikko et al., 2017). Digitalization is difficult to insulate from the enterprise at large, as it directly, and often profoundly, affects organizational processes and business models. New contracts based on service provision rather than product retail may also harm customer relations. The effects can, however, be mitigated so as not to affect or displace core competencies. A car manufacturer will still need to know how to 
Table 1. Study participants

\begin{tabular}{|c|c|c|c|}
\hline Type of firm & Name of firm & Industry & Role of respondent \\
\hline \multirow[t]{8}{*}{ Product-oriented } & P01 & Heavy machinery & Responsible for loT solutions \\
\hline & & & Responsible for service development \\
\hline & & & Division manager, IT \\
\hline & P02 & Heavy machinery & After-sales manager \\
\hline & & & Division manager, IT \\
\hline & P03 & Professional appliances & Division manager \\
\hline & & & After-sales manager \\
\hline & P04 & Professional appliances & Responsible for loT solutions \\
\hline \multirow[t]{6}{*}{ Service-oriented } & S01 & Facility management & Innovation manager \\
\hline & SO2 & Payment solutions & СТО \\
\hline & $\mathrm{SO3}$ & Transportation & Manager loT solutions \\
\hline & SO4 & Resort management & $\mathrm{ClO}$ \\
\hline & S05 & Facility management & IoT strategist \\
\hline & S06 & Facility management & Systems technician \\
\hline \multirow[t]{9}{*}{ Technology-oriented } & T01 & Telecommunications & IoT business developer \\
\hline & T02 & Connectivity and cloud solutions & CEO \\
\hline & & & СТО \\
\hline & T03 & Connectivity and cloud solutions & CEO \\
\hline & T04 & Connectivity and cloud solutions & CEO \\
\hline & T05 & Smart sensors & СТO \\
\hline & T06 & Smart sensors & СТО \\
\hline & T07 & Smart sensors & СТO \\
\hline & T08 & Interface design & CEO \\
\hline
\end{tabular}

build cars regardless of whether they are sold, leased, or shared in a pool.

Digital transformation is the sociocultural process of adapting firms to the new organizational forms and skill sets needed to remain viable and relevant in a digital landscape. It goes beyond earlier conceptions such as change enabled through information technology (IT) (Benjamin \& Levinson, 1993) or through business-process reengineering (Grover, Jeong, Kettinger, \& Teng, 1995), which seek to improve upon existing processes. Rather, digital transformation may be described as a "process that aims to improve an entity by triggering significant changes to its properties through combinations of information, computing, communication, and connectivity technologies" (Vial, 2019, p. 121). The use of the word "culture" is by no means hyperbolic. A survey of digital maturity including some 4,800 business executives found attitude rather than access to technology to be the decisive factor, highlighting that "[a] culture conducive to digital transformation is a hallmark of maturing companies" (Kane et al., 2015 , p. 9). The different ways in which digital technology is perceived to create value resonate deeply with previous research that showed how the value of IT is realized in economic gains, process improvements, and enhancements to the brand name that tie customers more closely to the firm (Kohli \& Grover, 2008). That is, much of the focus has been on how the customer-provider dyad can be developed and strengthened. But recent research has also demonstrated that cutting-edge amalgams of physical products and digital resources, such as the loT (Saarikko et al., 2017), artificial intelligence (Kaplan \& Haenlein, 2019), and machine learning (McAfee \& Brynjolfsson, 2017), are complex phenomena requiring new intellectual resources that are often beyond the capabilities of any one firm. Hence, in addition to significant changes to the internal workings of firms, digital transformation also pushes innovation beyond organizational boundaries into external innovation networks (Prince, Barrett, \& 
Oborn, 2014; Westergren, Holmström, \& Mathiassen, 2019) or ecosystems (Jacobides, Cennamo, \& Gawer, 2018; Rong, Hu, Lin, Shi, \& Guo, 2015).

The three digital domains may seem straightforward at first glance, but they all hide layers of complexity amid their implications for value creation, technology management, business strategy, and organizational culture. This article builds on an empirical study of firms and their attempts to make sense of digital transformation as new technology investments bring their digital concerns from back-office IT departments to executive boardrooms as well as frontline operations.

\section{Interviews}

The authors performed interviews with firms in various stages of digital transformation as they implemented IoT devices into their business models. We conducted semistructured interviews with 23 representatives from 18 firms that differed in size, industry, and market offering. The respondents were all involved in their respective firms' loT adoption and implementation processes, and were either C-level management themselves, or reported directly to $\mathrm{CIO}$ or CTOs. Table 1 gives an overview of our data set. The interviews lasted from 30 minutes to 90 minutes and averaged 45 minutes. All interviews were recorded and then transcribed. Furthermore, six firms demonstrated their loT-based systems, which gave us a deeper understanding of how different technologies and data sources interact to create smart solutions and machine learning that provide benefits for providers as well as customers. Finally, company websites and documentation provided by respondents provided additional contextual information pertaining to each enterprise and its domain.

We performed the data analysis in two stages using ATLAS.ti software. First, we performed an incase analysis for each firm (Eisenhardt, 1989), in which we searched for patterns and repeated statements in the data to gain insights into the specific firms. Previous research has shown that there are three basic types of firms within loT ecosystems: product-, service-, and technologyoriented firms (Burkitt, 2014; Saarikko et al., 2017). At this stage of the analysis, we therefore categorized each firm into one of these three types. In the second stage, we searched for common patterns and divergent stances between and within the three different types of firms. By applying multiple lenses and moving back and forth from specific firms to collective insights, we avoided settling for initial impressions and were able to stay close to the data. Our conclusions are drawn from the synthesis of the data analysis and the literature. Some specific quotes from the interviews are used to highlight certain details, and all company names have been anonymized in order to protect privacy.

\section{Voices from the field}

The loT is a suitable empirical context in which to study digital transformation, as it marks a new technological paradigm that disrupts organizations and markets (Krotov, 2017; Porter \& Heppelmann, 2015), forcing firms to revisit old truths and acquire new capabilities. IoT solutions require several distinct skill sets that, at a minimum, pertain to product design and manufacturing, service development, and connectivity and IT infrastructure (Saarikko et al., 2017). The firms in our study belong to one of three categories: product-oriented firms, whose main business has been delivering specific products for either a business or consumer market; service-oriented firms, whose main business has been service provision to other business and to consumers; and technology-oriented firms, which create connected devices, sensors, and other technology that enable connectivity and collection of data. All of the firms had implemented various loT solutions into their business practices and were busy working on their strategies for digital transformation in order to fully take advantage of the opportunities afforded by new technological developments.

\subsection{Product-oriented firms}

The product-oriented firms included in this study are all large, firmly established enterprises that dwell within a single industry or a limited number of industries. Their long-standing history within said industries is reflected in their respective skill sets: They are exceedingly adept at what they have been doing for decades. Furthermore, they have had little incentive to do anything else, as they have operated in industries and markets that have been reluctant to embrace major change.

The advent of disruptive technologies such as IoT has disturbed this rather comfortable status quo. Third-party providers that are wholly unaffiliated with manufacturing firms have started retrofitting products with remote connectivity in order to enable services that range from basic GPS positioning and fuel-efficiency algorithms to advanced systems that combine multiple data 
sources, such as position, weather, time, and temperature. This is particularly salient for $\mathrm{P} 1, \mathrm{P} 2$, and $\mathrm{P} 4$, who have seen this phenomenon gain momentum for several years. The result of this development is twofold. First, it has transferred some of the market influence away from the product provider and into the hands of the customer. As third-party solutions are brandagnostic, customers are able to apply the same solutions and services across their entire inventory of equipment or fleet of vehicles irrespective of manufacturer. Second, the appearance and proliferation of third-party solutions clearly indicate a change in the business climate for which the manufacturers themselves are ill prepared. There are evidently opportunities for new business models - and thus for profits to go into someone else's pockets. We were able to discern two distinct attitudes toward this phenomenon. P1 and P2 were quite restrictive and exhibited a possessive attitude toward the data generated by their products, whereas $\mathrm{P} 4$ was considerably more open to including other parties.

We don't want people tinkering with our products, and it would be better if thirdparty firms found different niches ... It could be that they focus on a particular market segment and build systems for that type of users, and utilize the APIs that we provide and pay a license fee to us. [P1, responsible for loT solutions]

It's entirely possible that service-oriented firms can access data and monopolize product-related service development. We as product-providers consider that scenario as well. So we're looking at competition or cooperation. I think that the only way to success here is cooperation between product manufacturers and suppliers of service and support. We simply have to realize that we have to let everyone get a piece of the pie. If not, we're going to get in each other's way and that's not the way forward. [P4, responsible for loT solutions]

In essence, mature product-oriented firms consider themselves at risk of getting demoted from trusted partners to mere providers of hardware. The prospect is not at all appealing, as all the product-oriented firms featured in our study are premium brands that strive to compete through quality and reliability rather than mere retail price. Moreover, they have all developed extensive in-house capabilities and dedicated departments to handle product R\&D and similar critical activities. Activities less related to brand identity but important to production and retail are managed through long value chains populated by trusted suppliers and contractors. While this operational necessity can be a potent barrier to entry for direct competitors, the same value chains can also shackle firms to a particular mindset that is focused on streamlining rather than innovation. The legacy of closed systems and in-house development that once was a source of leverage can suddenly become a drawback as customers start demanding something different.

It's typical of old companies built by engineers that you think your way is the right way. But at the same time, our products do contain an assortment of components built by other suppliers. So it's really not in our nature to do everything by ourselves. By the typical approach, as you've seen if you study different manufacturers, is to try do it yourself at first. [P4, responsible for loT solutions]

There is, however, one significant point on which all product-oriented firms agree: They are all sanguine about furnishing their products with remote connectivity, as hard data helps to justify high retail prices. If they can show that their products are more dependable thanks in part to smart services, then they will have an easier time justifying their higher retail price relative to cheaper alternatives. The idea of backing up qualitative claims with quantitative data feeds into the idea of strengthening the brand and forming a closer relationship with the customer. Furthermore, if a firm's product leaves the factory with remote connectivity already installed, it can eliminate or severely limit the appeal of retrofitted solutions, as they become effectively redundant. But while all the firms included in our study have begun incorporating the appropriate hardware for remote supervision, they have yet to match the more advanced services offered by the aforementioned third-party solutions. Thus far, their core service offerings amount to detection of anomalies-for example, cases of product breakdown, misuse, or theft.

We gather a whole lot of data, really. We don't actually use it anywhere near as much as we could. But we're trying to become smarter and smarter. So just like you said, we try to see if the driver's doing something strange, or if the machinery is somehow acting up. [P2, division manager, IT] 
One issue that has yet to be resolved pertains to the ownership of said data. On this particular issue, $\mathrm{P} 1, \mathrm{P} 2$, and $\mathrm{P} 3$ hold a somewhat possessive stance, either claiming data ownership or explicitly asserting the right to access product data whenever customers enter into service contracts. P4 maintains that data ownership per se should not be a priority; rather, the priority should be to ensure that information is accessible to multiple actors so that the product is compatible with different business models (e.g., leasing and direct retail) and different types of customers (e.g., business-to-business or business-to-consumer).

\subsection{Service-oriented firms}

The service-oriented firms included in our study were more positive toward the loT as a general trend because they have no vested interests in any particular products. But all six firms agreed regarding the main barrier to widespread adoption: the overall lack of common standards and interoperable systems. S2 and S4 face the most severe restrictions: S2 wrestles with a patchwork of legacy banking systems, while S4 faces safety regulations and certifications that prohibit even the most basic integration between systems at their resorts. The remaining firms are less confined by their business contexts but must still contend with significant technical hurdles. The lack of common standards or application programming interfaces often requires case-by-case integration between different systems and technologies, which can entail high risk and first-mover costs. Several of the service-oriented firms included in our study, most notably S1 and S3, operate in market segments that offer low profit margins. Hence, these firms seldom undertake any investment (loT-related or otherwise) unless they can be certain that it will yield tangible returns in the form of reduced operating costs or a competitive edge.

We see an incredible range of possibilities with loT. The current limitation is basically to get a hold of a horizontal platform [that can handle multiple systems]. Alternatively, there are a lot of different systems in the market these days, but individually they do not provide the overall benefit needed to outweigh the costs of managing and supporting multiple systems. [S1, innovation manager]

Due to the nature of their businesses, serviceoriented firms are keen to derive operational benefits from using smart technology in service provision. The service industry is labor-intensive, with service staff performing all manner of tasks that cannot be automated. While a personalized touch is part of service provision, firms spend a significant amount of time and effort checking whether service is actually needed. Leveraging advanced algorithms and learning systems to analyze sensor data would permit these firms to maintain or even improve upon current service levels at lower costs. For instance, S1 and S6, who are both within facility management, see significant potential for process improvement if they can perform service tasks when and where they are actually needed, as opposed to scheduling tasks based on their best guesses. S5 describes how a single sensor installed on the roof of a building can provide automated updates regarding external conditions, enabling a wealth of useful insights:

What we're doing now is installing snowsensors onto rooftops. Sending an engineer with a five-year college degree up to check the amount of snow on the rooftop is going to be pretty expensive, so we thought that 'we'll install an automated sensor instead, and it will gauge the snow depth' ... You can also look at development over time, for instance 'hold on - if it's three degrees below freezing and I had three feet of snow on my roof, and now two days later it's only two feet of snow. What's going on?' Well, it's likely that your roof is poorly insulated and is venting heat. Following that, you can immediately ask yourself 'where did the snow that melted go? Are there pools of water sitting on my roof, or do I need to worry about icicles hanging off the sides?' So, just by measuring snow depth, you can find out all kinds of things that you didn't know. [S5, loT strategist]

Although recent technical advances have ignited much interest in connecting products to the internet or outfitting buildings with smart sensors, the service industry has been using some of the technologies associated with the loT (e.g., RFID tags) for many years. But the proliferation of smart sensors necessitates a different approach, as it would be unethical to deploy sensors that continuously gather data on the activities of specific individuals without their consent. Furthermore, the legal frameworks that govern these types of surveillance are not yet mature and are subject to change based on political discourse or public concern. The service providers included in our 
Table 2. Summary of results

\begin{tabular}{|c|c|c|}
\hline Digital domain & Digital concerns & Empirical findings \\
\hline \multirow[t]{5}{*}{ Digitization } & $\begin{array}{l}\text { Incremental } \\
\text { changes }\end{array}$ & $\begin{array}{l}\text { Minor digital features are introduced in new offerings in order to give the } \\
\text { appearance of novelty. }\end{array}$ \\
\hline & $\begin{array}{l}\text { Data as persistent } \\
\text { resource }\end{array}$ & $\begin{array}{l}\text { Extracted data can be used for multiple purposes and on multiple } \\
\text { occasions. }\end{array}$ \\
\hline & $\begin{array}{l}\text { Necessity of } \\
\text { partnerships }\end{array}$ & $\begin{array}{l}\text { Cutting-edge capabilities can be acquired more quickly and easily through } \\
\text { partnerships with external organizations. }\end{array}$ \\
\hline & Lack of standards & $\begin{array}{l}\text { The lack of agreed-upon standards serves to inhibit uptake of new } \\
\text { technologies, as each actor has to spend time and resources solving basic } \\
\text { interoperability issues. }\end{array}$ \\
\hline & Data hoarding & $\begin{array}{l}\text { Large quantities of data are gathered and stored without a clear } \\
\text { understanding of their purpose or value. }\end{array}$ \\
\hline \multirow[t]{5}{*}{ Digitalization } & $\begin{array}{l}\text { Business-model } \\
\text { modification }\end{array}$ & $\begin{array}{l}\text { The influx of new technologies provokes shallow or profound adjustments to } \\
\text { the firm's business model. }\end{array}$ \\
\hline & Business myopia & $\begin{array}{l}\text { An inability to develop new business models and revenue streams based on } \\
\text { data. }\end{array}$ \\
\hline & $\begin{array}{l}\text { Digital } \\
\text { newcomers }\end{array}$ & $\begin{array}{l}\text { Stable market structures are disrupted by new entrants who leverage } \\
\text { digital technology to appropriate unexplored business opportunities. }\end{array}$ \\
\hline & $\begin{array}{l}\text { Spectrum of } \\
\text { improvements }\end{array}$ & $\begin{array}{l}\text { Digital technology offers many distinct opportunities, ranging from minor } \\
\text { improvements to major reengineering, benefitting frontline employees or } \\
\text { centralized management. }\end{array}$ \\
\hline & $\begin{array}{l}\text { Value-chain } \\
\text { inertia }\end{array}$ & $\begin{array}{l}\text { Mature firms accustomed to working with linear value chains have difficulty } \\
\text { adapting to ecosystems and cocreation often found in digital economies. }\end{array}$ \\
\hline \multirow[t]{6}{*}{$\begin{array}{l}\text { Digital } \\
\text { transformation }\end{array}$} & $\begin{array}{l}\text { Lack of clear } \\
\text { vision }\end{array}$ & $\begin{array}{c}\text { New technology is introduced on a case-by-case basis without a long-term } \\
\text { strategy. }\end{array}$ \\
\hline & $\begin{array}{l}\text { Customer } \\
\text { expectations }\end{array}$ & $\begin{array}{l}\text { New technology is introduced because of external pressure rather than } \\
\text { internal strategy. }\end{array}$ \\
\hline & $\begin{array}{l}\text { Outcome } \\
\text { ambiguity }\end{array}$ & $\begin{array}{c}\text { Actors are reluctant to enact transformative change, as it is perceived to be } \\
\text { a gargantuan, long-term project with uncertain outcomes. }\end{array}$ \\
\hline & $\begin{array}{l}\text { Familiarity over } \\
\text { innovation }\end{array}$ & $\begin{array}{l}\text { Significant innovations and departures from the status quo are easier to } \\
\text { accept from mature, established actors than from niche firms, even though } \\
\text { the latter often offer more advanced solutions. }\end{array}$ \\
\hline & $\begin{array}{l}\text { Sociotechnical } \\
\text { misalignment }\end{array}$ & $\begin{array}{l}\text { Technological development far outpaces other aspects of society, leading } \\
\text { to a fundamental mismatch between what technology permits us to do and } \\
\text { our ability to grasp its consequences. }\end{array}$ \\
\hline & Cultural inertia & $\begin{array}{l}\text { Mature firms are often reluctant to engage in partnerships or look outside } \\
\text { their own circles for new capabilities. }\end{array}$ \\
\hline
\end{tabular}

study were all very clear that they did not want to bear the risk of violating current or future laws by recording personal data-nor do they want to shoulder the responsibility for warding off unauthorized access to sensors for illicit surveillance. Their response to this issue is to use sensors that are deliberately unspecific; for example, a sensor may be able to register movement but not a person's height, weight, or other distinguishing features. Even when user data is anonymized and reduced to numbers in a system, service providers offer quite different perspectives on how they would like to leverage said data. S1 and S6 are relatively homogeneous enterprises where similar, often-routine tasks are performed by different staff in different locations. Consequently, these enterprises see the value of a "dashboard" of sorts that can provide a quick overview and status updates from a central office. In time, machine learning and automated responses may reduce the need to manually assess and respond to routine operations. On the other hand, S4 is a considerably more heterogeneous organization that considers IoT and smart sensors a way to empower frontline 
employees in their respective tasks. When coupled with algorithms that can identify clusters and bottlenecks, sensor data may be useful for S4's long-term planning-for example, by ensuring that the most heavily trafficked areas are equipped with adequate restrooms and similar essential facilities.

\subsection{Technology-oriented firms}

All the technology-oriented firms featured in this study-with the notable exception of $\mathrm{T} 1$-are small or medium enterprises. They differ significantly in orientation and occupy different niches that collectively make up the requisite technologies to enact digitized products and digitalized business models. T1 provides the information infrastructure (e.g., 4G communications networks) that is needed to transmit data from remote locations. T2, T3, and T4 design cloud solutions that can accommodate robust connectivity and handle the massive quantities of data generated by connected devices. T5, T6, and T7 design sensors for deployment in an array of environments, from modern office spaces to mine shafts. Finally, T8 aggregates data and produces interfaces that suit the needs of different user groups.

While the recent surge in interest surrounding the loT has forced product and service providers to stop and consider their options, the technologyoriented firms featured in our study are cautiously optimistic. One recurring theme among all these firms was the emergence of new opportunities to apply existing skill sets in new industries and market spaces. T4 provides an illustrative example. The firm used to develop and manage systems for online gambling, and in doing so, it learned to build scalable back-office systems, handle payment systems that can accommodate multiple currencies, and develop intuitive user interfaces. Today, the very same skills are invaluable in building a platform that can collect and analyze data from a steadily rising number of connected units without causing system instability or requiring a proportional increase in support staff.

We learned a lot about designing systems that are scalable and secure, the ability to process different currencies, and to design user interfaces ... Almost by accident, we ended up consulting for [a product manufacturer] as they were designing an onlinefeature of their own. [ ... ]loT wasn't really the widely used expression back then, and we realized that we were one of few companies that had actually produced something tangible. [T4, CEO]

Even though most of these technology-oriented firms can be described as mature (all but T4 have been around for 10 years or more), very few of them have attained any significant brand recognition. The exception is T1, which is a large enterprise with a familiar brand. The disconnect between technical proficiency and brand recognition is a significant factor for many tech-savvy small and medium enterprises. Prospective customers are hesitant to adopt a technology that they do not fully comprehend, and they are even less inclined to accept an offer from an unfamiliar firm. As such, technology-oriented firms are keen to engage in partnerships or participate in ecosystems backed by larger, more familiar firms.

Unlike the product and service providers we studied, the technology-oriented firms expressed no real interest in owning or accessing customer data. While they acknowledge that it is well within their capability to store data generated by customers, they generally prefer to position themselves as impartial and as sources of customer empowerment, not exploitation. As such, technology firms make an explicit distinction between the act of gathering and forwarding data in real time, and the process of analyzing data to discern patterns or long-term trends, even though both activities are enabled by the same technology. A couple of the firms we studied, T2 and T5, went so far as to claim that they absolutely do not want to be responsible for storing or managing customer data. Their role is only to process and forward data in a manner specified by the customer.

\subsection{Summary of case findings}

As our study includes firms that differ in orientation as well as in size and scope, it naturally follows that they represent a wide range of conditions, perspectives, interests, and ambitions. The empirical findings can for analytical purposes be separated and attributed to the domains of digitization, digitalization and digital transformation. A summary of the results is provided in Table 2.

Our study reveals a number of challenges related to business strategy (e.g., changing business models and threats from newcomers) and technical issues (e.g., standardization and aimless data hoarding), as well as distinctly "soft" issues stemming from industry norms and corporate culture. The common theme is the general perception of digital technology as a disruptive force that 
some perceive as a catalyst for opportunity, while others see risks stemming from the scope and uncertainty associated with transformative change. Both perspectives derive from the peculiar nature of digitized data as an ephemeral yet reusable and infinitely renewable resource that has change$\mathrm{d}$-and continues to change-how we conduct business. The effects range from minor tweaks and improvements to existing processes to profound changes to the very essence of business models-for example, changing market offerings from retail products to providing a service or function.

\section{Five recommendations for becoming digitally conscious}

Digital transformation often pushes enterprises out of their comfort zones by forcing long-term strategic choices about an unpredictable future (Nylén \& Holmström, 2015). On the basis of our empirical findings and a review of extant research, we present five recommendations for developing digital consciousness within firms that are engaged in digital transformation.

\subsection{Start small and build on firsthand benefits}

Digital transformation is a comprehensive term that describes the ability of an organization to leverage digital technology to improve the efficiency and efficacy of its internal operations and external market offerings (Vial, 2019). As such, digital transformation is prone to being associated with paradigm-shifting technologies such as artificial intelligence, machine learning, or big data, all of which require significant up-front investments in time, money, and staff before any significant benefits can be realized (Lee, 2017; McAfee \& Brynjolfsson, 2017).

In this article, we describe digital transformation as a sociocultural process rather than as a technical feat. That is not to say that technology is unimportant, but rather that the drivers of transformation are organizational culture and ideas rather than technological savviness. The service-oriented firm that installed sensors on rooftops to measure snow depth speaks to our point in that the technical solution is often simple. Aggregating the data from a handful of sensors across different buildings does not require advanced databases or analytical support; it can quite easily be monitored by either a local building manager or a facility management office.
The transformative aspect is not expressed in the technical artifact itself but rather in the insight needed to identify the benefits that can be derived from using a digital tool to solve a business problem. Moreover, a defining characteristic of digital technology is the ability to increase the density of information and the knowledge resources that may be brought to bear on any single set of data (Lusch \& Nambisan, 2015). That is, any phenomenon that may be represented by bits and bytes can instantaneously be transported across vast distances and analyzed by someone with an entirely different perspective and set of experiences. An additional transformative property of the digitally conscious firm is the ability to realize this potential and to treat data as an interdisciplinary resource that is not consumed upon use but that can be leveraged to extract multiple benefits depending on context. Hence, the name of the game is not to indiscriminately gather big data but rather to carefully gather the right data for the firm's needs and to build on the benefits that they bring.

\subsection{Team up and create competitive advantage from brand recognition}

The digitization of the physical world holds much untapped business potential (Brynjolfsson \& McAfee, 2014). Even so, its practical implementations are in many regards still considered a relative novelty within many market segments and industries. Even if the underlying technology is mature and robust, it still carries with it a perceived risk within established firms, as the more innovative solutions often come from small tech firms and entrepreneurs, which are more agile. While extant research has highlighted how judicious use of IT can enhance a company's brand name (Kohli \& Grover, 2008), our study suggests that a strong brand name is a prerequisite for engaging customers in transformative efforts, innovative business models, and new market offerings. That is, firms that already have a strong brand name have a head start when it comes to incorporating connected products or machine learning into their business, thanks to their installed customer bases and high credibility in their fields. Participation in an ecosystem may serve to mitigate risk and to create a win-win situation, whereby established firms get fast access to technological know-how and new business models, while small tech firms with less familiar brands may make use of their partners' strength to establish a foothold from which to gradually build their own credibility and to scale up their 
offerings. An established brand is indeed a powerful resource in the face of the risks and uncertainties that come with new technologies and market offerings. But there are limits to how far you can stretch customer loyalty and patience. Product-oriented firms are especially vulnerable to inaction and failure to move with the times. Impatient customers may start looking for workarounds and third-party options if brandsanctioned, first-party solutions fail to materialize within an acceptable time frame. In the end, failure to move with the times may serve to devalue the brand and to pave the way for new, ITliterate competitors, just as the conservative automotive industry did for Tesla.

\subsection{Engage in standardization efforts}

Digital innovation is based on the ability to combine a large number of digitized technologies that are, when viewed in isolation, relatively mature and easy to deploy. But in practice, things are rarely so simple. Digital transformation relies on an organization's capability to acquire, deploy, and maintain several distinct technologies in parallel without becoming overwhelmed. The loT illustrates the point, in that a hierarchy of technologies need to work together, from the smallest sensor or RFID tag to large cloud servers and back-office systems (Borgia, 2014). Connecting a wide variety of technologies may bring about a patchwork wherein individual integrations are sound and sensible, but they can be difficult to oversee or stress-test due to the sheer size of the system and the scope of its implementations. Moreover, technical infrastructures and new market offerings are increasingly developed through partnerships or in ecosystems, further stressing the sociocultural nature of digital transformation. This gives rise to diverging and often conflicting strategic interests of different firm types (Saarikko et al., 2017). Technology-oriented firms want their offerings to be applicable to a range of different firms and in dustries. Product-oriented firms, on the other hand, are more interested in distributing loT solutions as part of their own line of products in hopes of enticing customers to opt for multiple, technically compatible products from the same supplier. If different enterprises pool their intellectual and material resources, they can begin to develop standards and interfaces that may become widespread within an industry or market. In time, standards can disseminate into other contexts as well, accumulating legitimacy and strength along the way. We may draw comparisons to the internet, which gradually grew through small, incremental additions and improvements by independent stakeholders into the global network that we see today. Given the pervasive and enduring influence of standards, the digitally conscious firm should ensure that their interests are reflected in standards' development and enactment. Otherwise, they may find themselves out of the loop and working in a technological landscape that runs counter to their strategic interests, as when customers began retrofitting vehicles with third-party solutions over which the vehicle providers had no influence or control. Hence, standardization is not merely a matter for the engineering department; it also has a significant strategic component that should attract the attention of corporate management.

\subsection{Take responsibility for data ownership and ethics}

While the wholesale creation of data is not the key defining feature of digital transformation, it is an inescapable consequence of working with digitized products and digitalized business models. With thousands or millions of connected products, firms have a golden opportunity not only to provide connectivity solutions but also to capture a bigger part of a market, one that increasingly derives its revenues from services based on collected data. Because digitized products and services can be used for business and consumer purposes simultaneously, firms have every opportunity to create win-win solutions that cater to both sides and generate multiple types of value. One of the unanswered questions of digital transformation is where to draw the line. Smart products and connected environments are capable of gathering a significant amount of data on individuals. While single data points may be harmless, the routine gathering of data from multiple sources and the compiling of detailed digital profiles on people, whether customers or employees, have troubling implications (Weinberg, Milne, Andonova, \& Hajjat, 2015).

The ethical quandary is twofold. First, while individuals may consent to sharing individual scraps of information about themselves with organizations with which they interact, this does not entitle any one actor to combine data from various firms or to compile a comprehensive image of consumers' activities. Second, such information has considerable destructive potential should it fall into the wrong hands. An increased awareness of the responsibilities of data management is a watershed with regard to a firm's digital maturity. While some actors are eager to gather as much data as they can, we note that the more technology-savvy firms are notably less keen to 
assume ownership and responsibility for user data. While they identify real-time data capture and long-term data analysis as two separate values enabled by the same technology, they are hesitant to embrace the latter. They do not want to get embroiled in the legal hassles and responsibilities that come with data ownership, preferring to transfer accountability to someone else. $\mathrm{Ng}$ and Wakenshaw (2017) used the term "socio-cyberphysical offerings" to describe digitized offerings and digitalized business models. Our study suggests that successful digital transformation requires recognition of the legal dimension, leaving us with the cumbersome label of socio-cyberphysical-juridical offerings. Hence, digital transformation entails careful consideration of the legal and practical implications of data ownership and management.

\subsection{Own the change and ensure organization-wide commitment}

Previous research has shown that digital technology creates both tangible and intangible value (Nambisan, 2013). But in the context of digital transformation, value is only extracted through a conscious and deliberate entanglement of physical, technical, and social systems $(\mathrm{Ng} \&$ Wakenshaw, 2017). As the survey by Kane et al. (2015) demonstrates, corporate culture is a significant component in embracing and exploiting digital technology in transformative efforts. The firms in our study perceived digital transformation as a significant departure from current practices and were very aware of the risk of cultural inertia and sociotechnical misalignment stemming from misconceptions of what the technology could and would do. They stressed the importance of ensuring organization-wide commitment and of making sure technological development is grounded in both strategy and practice. By implementing loT solutions, they came to see the possibility of breaking with tradition and of moving from linear value chains to value networks. Such a move, however, entails having a clear vision and taking into consideration the idiosyncratic nature of each firm, including current corporate practices, norms, and business values. Furthermore, it requires leadership and endorsement from top management. Ultimately, we have seen that

Figure 2. Digital domains and becoming digitally conscious

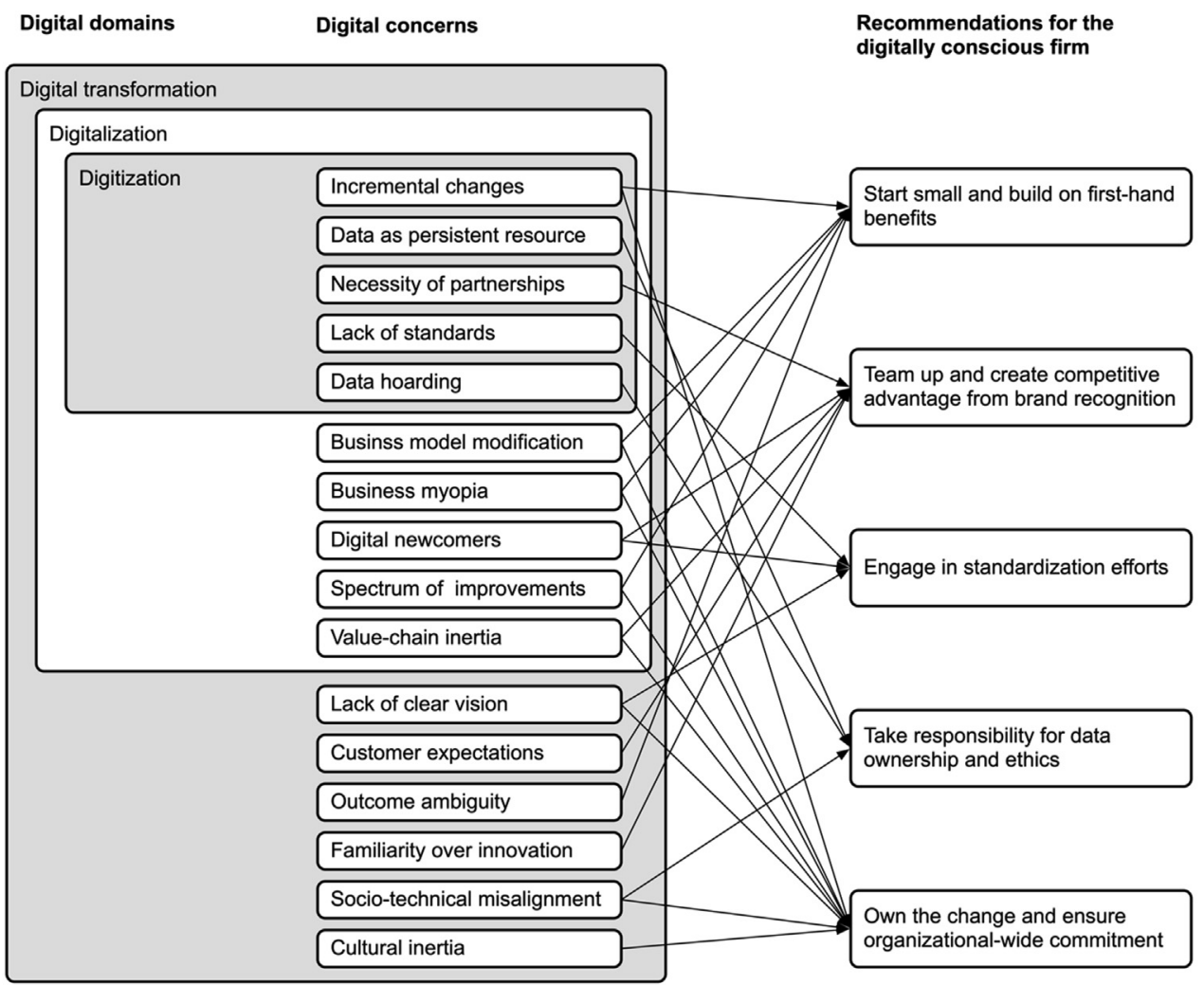


digital changes to the organization, its business practices, or its products and services cannot be ends unto themselves but must be means to an end. To reduce outcome ambiguity, digitaltransformation efforts must be established by top management, firmly entrenched in middle and lower management, and allowed to permeate all aspects of organizational life. Raising the level of digital consciousness can thereby produce substantial improvement in the firm's ability to leverage digital technology and own the change.

\subsection{The five recommendations}

Digital transformation is a complex phenomenon encompassing different types of technologies, firms, and management strategies. Our five recommendations for becoming digitally conscious are inextricably linked in practice. As such, they cut across all three domains: digitization, digitalization, and digital transformation. Figure 2 shows the linkages between digital domains, digital concerns, and the five recommendations.

\section{Conclusion}

Embracing digital transformation requires firms to identify what technologies are relevant and how they will be enacted in business offerings. As digital technology burrows deeper into organizational processes and market offerings, it will inevitably affect business strategies as firms reevaluate their perceptions of themselves as well as their relationships with partners and customers. In this article, we have used the loT to illustrate the risks and potential of new, potentially disruptive technologies, and we have empirically explored firms' conceptions of digital transformation. Based on our research, we offer five recommendations for firms to consider when formulating digitally conscious strategies that combine technological advancements with business practice and organizational culture:

1. Start small and build on firsthand benefits.

2. Team up and create competitive advantage from brand recognition.

3. Engage in standardization efforts.

4. Take responsibility for data ownership and ethics.

5. Own the change and ensure organizationwide commitment.
In so doing, we have shown that developing digital consciousness and embracing digital transformation requires taking into account social, technical, and organizational factors and firmly grounding them in both strategy and practice. These five recommendations are inclusive but not exhaustive. Future research should therefore elaborate on the opportunities and challenges of digital transformation across different firm types and within different technological paradigms.

\section{Acknowledgments}

This study was made possible through a grant from VINNOVA.

\section{References}

Baines, T., \& Lightfoot, H. W. (2013). Servitization of the manufacturing firm: Exploring the operations practices and technologies that deliver advanced services. International Journal of Operations and Production Management, 34(1), 2-35.

Balakrishna, C. (2012). Enabling technologies for smart city services and applications. In Proceedings of the $6^{\text {th }}$ International Conference on Next Generation Mobile Applications, Services, and Technologies (pp. 223-227). Paris, France: IEEE.

Benjamin, R. I., \& Levinson, E. (1993). A framework for managing IT-enabled change. Sloan Management Review, 34(4), 23-33.

Borgia, E. (2014). The Internet of Things vision: Key features, applications, and open issues. Computer Communications, $54,1-31$.

Brody, P., \& Pureswaran, V. (2015). The next digital gold rush: How the Internet of Things will create liquid, transparent markets. Strategy and Leadership, 43(1), 36-41.

Brynjolfsson, E., \& McAfee, A. (2014). The second machine age: Work, progress, and prosperity in a time of brilliant technologies. New York, NY: WW Norton \& Company.

Burkitt, F. (2014). A strategist's guide to the Internet of Things. Strategy+Business, 77, 2-12.

Eisenhardt, K. M. (1989). Building theories from case study research. Academy of Management Review, 14(4), 532-550.

Greengard, S. (2015). The Internet of Things. Cambridge, MA: MIT Press.

Grover, V., Jeong, S. R., Kettinger, W. J., \& Teng, J. T. (1995). The implementation of business process reengineering. Journal of Management Information Systems, 12(1), 109-144.

Henfridsson, O., Nandhakumar, J., Scarbrough, H., \& Panourgias, N. (2018). Recombination in the open-ended value landscape of digital innovation. Information and Organization, 28(2), 89-100.

Hess, T., Matt, C., Benlian, A., \& Wiesböck, F. (2016). Options for formulating a digital transformation strategy. MIS Quarterly Executive, 15(2), 123-139.

Jacobides, M. G., Cennamo, C., \& Gawer, A. (2018). Towards a theory of ecosystems. Strategic Management Journal, 39(8), 2255-2276. 
Kane, G. C., Palmer, D., Phillips, A. N., Kiron, D., \& Buckley, N. (2015, July 14). Strategy, not technology, drives digital transformation. MIT Sloan Management Review. Available at https://sloanreview.mit.edu/projects/strategy-drivesdigital-transformation/

Kaplan, A., \& Haenlein, M. (2019). Siri, Siri, in my hand: Who's the fairest in the land? On the interpretations, illustrations, and implications of artificial intelligence. Business Horizons, 62(1), 15-25.

Kathan, W., Matzler, K., \& Veider, V. (2016). The sharing economy: Your business model's friend or foe? Business Horizons, 59(6), 663-672.

Kohli, R., \& Grover, V. (2008). Business value of IT: An essay on expanding research directions to keep up with the times. Journal of the Association for Information Systems, 9(1), Article 1.

Kortuem, G., Kawsar, F., Fitton, D., \& Sundramoorthy, V. (2010). Smart objects as building blocks for the Internet of Things. Internet Computing, IEEE, 14(1), 44-51.

Krotov, V. (2017). The Internet of Things and new business opportunities. Business Horizons, 60(6), 831-841.

Lee, I. (2017). Big data: Dimensions, evolution, impacts, and challenges. Business Horizons, 60(3), 293-303.

Lee, I., \& Lee, K. (2015). The Internet of Things (IoT): Applications, investments, and challenges for enterprises. Business Horizons, 58(4), 431-440.

Li, F. (2018). The digital transformation of business models in the creative industries: A holistic framework and emerging trends. Technovation, 92/93, Article 102012.

Lusch, R. F., \& Nambisan, S. (2015). Service innovation: A service-dominant logic perspective. MIS Quarterly, 39(1), 155-175.

Matt, C., Hess, T., \& Benlian, A. (2015). Digital transformation strategies. Business and Information Systems Engineering, 57(5), 339-343.

McAfee, A., \& Brynjolfsson, E. (2017). Machine, platform, crowd: Harnessing our digital future. New York, NY: WW Norton \& Company.

Muro, M., \& Maxim, R. (2018, December 4). What GM's layoffs reveal about the digitalization of the auto industry. Harvard Business Review. Available at https://hbr.org/2018/12/ what-gms-layoffs-reveal-about-the-digitalization-of-theauto-industry

Nambisan, S. (2013). Information technology and product/service innovation: A brief assessment and some suggestions for future research. Journal of the Association for Information Systems, 14(4), 215-226.

Nambisan, S. (2017). Digital entrepreneurship: Toward a digital technology perspective of entrepreneurship. Entrepreneurship: Theory and Practice, 41(6), 1029-1055.

Nambisan, S., Wright, M., \& Feldman, M. (2019). The digital transformation of innovation and entrepreneurship: Progress, challenges, and key themes. Research Policy, 48(8), Article 103773.

Ng, I. C., \& Wakenshaw, S. Y. (2017). The Internet-of-Things: Review and research directions. International Journal of Research in Marketing, 34(1), 3-21.

Nylén, D. , \& Holmström, J. (2015). Digital innovation strategy: A framework for diagnosing and improving digital product and service innovation. Business Horizons, 58(1), 57-67.

Porter, M. E., \& Heppelmann, J. E. (2014). How smart, connected products are transforming competition. Harvard Business Review, 92(11), 64-88.

Porter, M. E., \& Heppelmann, J. E. (2015). How smart, connected products are transforming companies. Harvard Business Review, 93(10), 96-114.

Prince, K., Barrett, M., \& Oborn, E. (2014). Dialogical strategies for orchestrating strategic in-novation networks: The case of the Internet of Things. Information and Organization, 24(2), $106-127$.

Rong, K., Hu, G., Lin, Y., Shi, Y., \& Guo, L. (2015). Understanding business ecosystem using a $6 \mathrm{C}$ framework in Internet-of-Things-based sectors. International Journal of Production Economics, 159, 41-55.

Saarikko, T., Westergren, U. H., \& Blomquist, T. (2017). The Internet of Things: Are you ready for what's coming? Business Horizons, 60(5), 667-676.

Tilson, D., Lyytinen, K., \& Sørensen, C. (2010). Research commentary - digital infrastructures: The missing IS research agenda. Information Systems Research, 21(4), 748-759.

Vial, G. (2019). Understanding digital transformation: A review and a research agenda. The Journal of Strategic Information Systems, 28(2), 118-144.

Weinberg, B. D., Milne, G. R., Andonova, Y. G., \& Hajjat, F. M. (2015). Internet of Things: Convenience vs. privacy and secrecy. Business Horizons, 58(6), 615-624.

Westergren, U. H., Holmström, J., \& Mathiassen, L. (2019). Partnering to create IT-based value: A contextual ambidexterity approach. Information and Organization, 29(4), Article 100273. 